\title{
The Wavelets show it - the transit time of water varies in time
}

\author{
Milan Onderka*, Vladimír Chudoba
}

Comenius University, Faculty of Mathematics, Physics and Informatics, Department of Astronomy, Physics of the Earth and Meteorology, Mlynská dolina, SK-842 48 Bratislava, Slovakia.

*Corresponding author. E-mail: milan.onderka@fmph.uniba.sk

\begin{abstract}
The ways how water from rain or melting snow flows over and beneath the Earth's surface affects the timing and intensity at which the same water leaves a catchment. Several mathematical techniques have been proposed to quantify the transit times of water by e.g. convolving the input-output tracer signals, or constructing frequency response functions. The primary assumption of these techniques is that the transit time is regarded time-invariant, i.e. it does not vary with temporarily changing e.g. soil saturation, evaporation, storage volume, climate or land use. This raises questions about how the variability of water transit time can be detected, visualized and analyzed. In this paper we present a case study to show that the transit time is a temporarily dynamic variable. Using a real-world example from the Lower Hafren catchment, Wales, UK, and applying the Continuous Wavelet Transform we show that the transit time distributions are time-variant and change with streamflow. We define the Instantaneous Transit Time Distributions as a basis for the Master Transit Time Distribution. We show that during periods of elevated runoff the transit times are exponentially distributed. A bell-shaped distribution of travel times was observed during times of lower runoff. This finding is consistent with previous investigations based on mechanistic and conceptual modeling in the study area according to which the diversity of water flow-paths during wet periods is attributable to contributing areas that shrink and expand depending on the duration of rainfall. The presented approach makes no assumptions about the shape of the transit time distribution. The mean travel time estimated from the Master Transit Time Distribution was $\sim 54.3$ weeks.
\end{abstract}

Keywords: Transit time distribution; Tracer; Chloride; Continuous wavelet transform; Non-stationary.

\section{INTRODUCTION}

The transit time of water became an important descriptor of catchment functioning due to its potential to affect many chemical and biological processes and also because it can reveal new phenomena in the process of runoff generation (Duffy et al., 1985; Heidbüchel et al., 2012; Kirchner, 2016; Kirchner et al., 2000, 2001; White, 1987). The distribution of water transit times improves our understanding of how catchments response to changes in land use, how fast a contaminant will decay, and how promptly a catchment will respond to altered management practices (Duffy et al., 1985; McGuire et al., 2002). Basically, every catchment can be characterized by its water transit time distributions (TTD) that reflect the diversity of flowpaths connecting each point on the landscape with a stream outlet (Benettin et al., 2015a, 2015b; Botter et al., 2011; Davies et al., 2013; Harman, 2015; Heidbüchel et al., 2012; Hrachovitz et al., 2010; Kirchner et al., 2001, 2000; McGuire and McDonnell, 2006; Tekleab et al., 2014). Some authors relate physiographic characteristics of catchments to the mean of water transit times (Dunn et al., 2007; Gomez and Wilson, 2013; Hrachowitz et al., 2010; Onderka et al., 2012; McGuire et al., 2005). As the mean transit time is only a central tendency measure, it cannot reveal much about the underlying distribution of all transit times, as it is the shape of the distribution of transit times that reflects the heterogeneity of flow paths and velocities (Hrachowitz et al., 2010; Kirchner et al., 2001, 2000; McGuire and McDonnell, 2006). A common assumption in estimating the transit time distribution is that the hydrologic conditions in a catchment under investigation are constant (Harman, 2015; Heidbuechel et al., 2012; Maloszevski and Zuber, 1983). However, this assumption is in most cases unjustified (Harman, 2015; Heidbuechel et al., 2012; Maloszevski and Zuber, 1983; McMillan et al., 2012; van der Velde et al., 2012; van der Velde et al., 2015), as the steady state approximation is applicable only when the dynamic part of the investigated system is small in comparison with the total volume of the catchment storage. Maloszewski and Zuber (1983) stated that a catchment can be considered as a steady state system when changes in flow rates are short in comparison with the duration of changes in tracer concentration. Other plausible mechanisms explaining the nonstationary nature of TTDs include e.g. activation of various flowpaths during the runoff generation (Heidbüchel et al., 2012), freezing/thawing of soil water, accumulation of snowpack and its subsequent snowmelt, and infiltration excess overland flow during extreme rainfall events and evaporation. Both time and frequency domains became popular for studying transit time distributions (Hrachowitz et al., 2009; Kirchner et al., 2000, 2001; Maloszewski and Zuber, 1983; McDonnell et al., 2010; McGuire and McDonnell, 2006; McGuire et al., 2002, 2005; Soulsby et al., 2014, 2015). However, in the time domain representation of a signal it is recognized that information about the frequency content of the signal is hidden. On the other hand, in the frequency domain analysis, the information about the temporal evolution of a signal gets obscured (Torrence and Compo, 1998). Unfortunately, the Fourier analysis does not allow us to examine the temporal variations in TTD. To overcome this problem, we use the Continuous Wavelet Transform (CWT). The key advantage of the CWT over the conventional Fourier methods or integral convolution is its ability to detect changes in the individual frequency components of a signal in time (Farge, 1992; Torrence and Compo, 1998). Our hypothesis is that by using CWT we can: 1) estimate the distribution of transit times in the lower Hafren catchment; and 2) quantify and visualize the nonstationary nature of transit times in contrast to the results from previous studies in the area (Kirchner et al., 2000, 2001). 


\section{MATERIALS AND METHODS}

Sources of data: To test our approach on real-world data we used the publically available datasets from the Plynlimon research catchments (Benettin et al., 2015a, 2015b; Kirchner et al., 2001; Neal, 1997; Neal et al., 2011, 2013), which are the most thoroughly investigated experimental catchments worldwide. The Plynlimon research catchments lie within the headwaters of the River Severn and the River Wye in the uplands of mid-Wales, UK. The Centre of Ecology and Hydrology, UK, made this database available to scientific research such as this one. These catchments were described in detail in Neal (1997) so we restrict the description of the dataset and the catchment only within necessary limits. More details can be found in Neal et al. (2011). Data from a headwater catchment (the Lower Hafren) were used in this study. The publically available dataset from the Plynlimon research catchment contain two sets: raw data, and edited data. In our analyses we used the edited data, where any problematic data values have been corrected or excluded. The edited data include only those measurements in which we have a high degree of confidence (https://data.gov.uk/dataset/plynlimon-research-catchmenthydrochemistry). The datasets we used include time-series of rainfall, runoff and chloride concentrations measured in bulk precipitation and stream water with a weekly sampling frequency. The catchment has a temperate maritime climate with precipitation primarily arriving from the Atlantic Ocean, with seasalt chloride inputs fluctuating substantially (Benettin et al., 2015a, 2015b; Kirchner et al., 2000; Neal, 1997). We assume that rainfall is the dominant input of chloride to the catchment. The catchment area is about $3.5 \mathrm{~km}^{2}$, and consists of about $60 \%$ forest and $40 \%$ moorland overlying Lower Paleozoic mudstone and shale with some glacial drift (Harman at al., 2015). Chloride concentrations measured in precipitation and in streamwater were chosen to represent the non-reactive tracer. Bulk precipitation was collected at Carreg Wen near the edge of the catchment in continuously open containers. No substantial anthropogenic sources of chloride are expected, making chloride an effective non-reactive chemical tracer originating mostly from rainfall (Benettin et al., 2015a, 2015b; Harman, 2015; Kirchner et al., 2000, 2001).

Signal analyses: First, the mass fluxes of chloride in rainfall and stream water were calculated. The observed time series of rainfall, runoff and chloride concentrations are shown in Fig. 1.

As rainfall is sampled in collectors, i.e. the amount of water collected is an integrated sample of precipitated water since the last read-out. The mass fluxes of chloride in rainfall were calculated by multiplying the amount of water collected over a
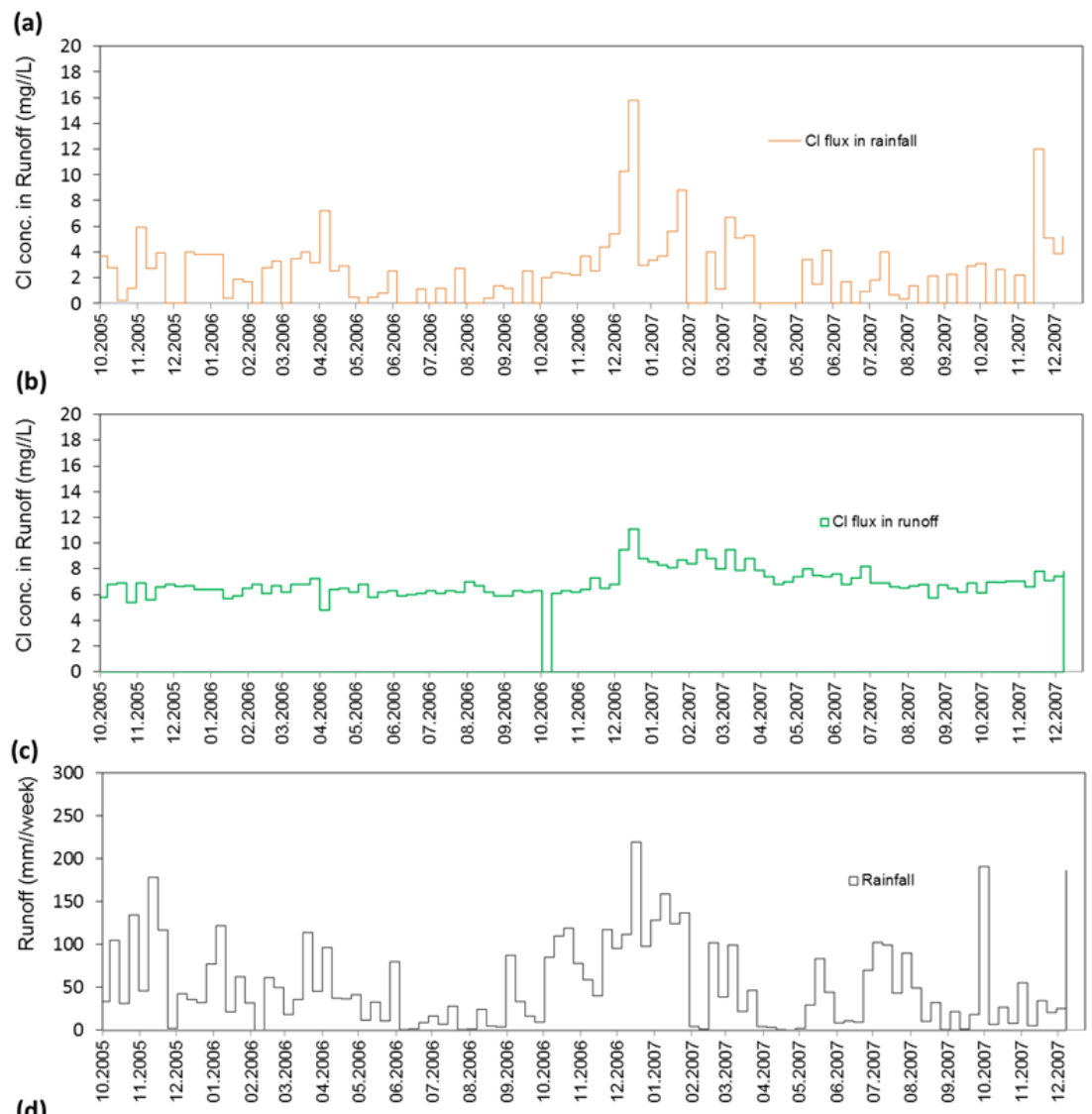

(d)

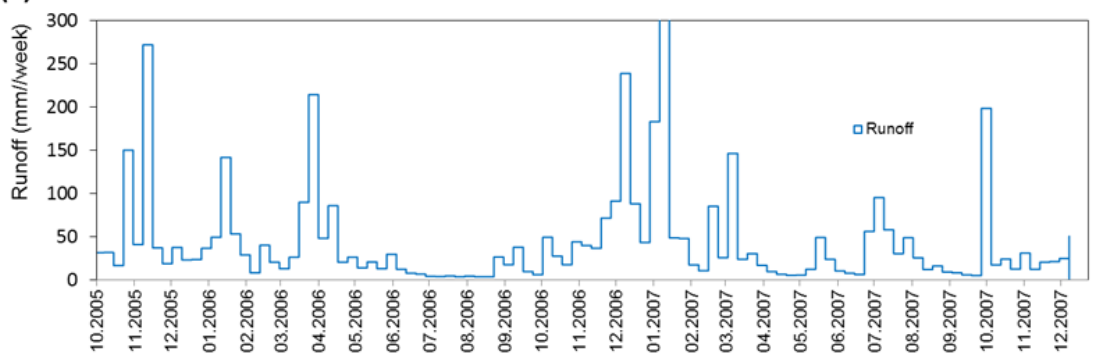

Fig. 1. Chloride concentrations in rainfall (a) and runoff (b). Weekly precipitation totals (c) and weekly runoff (d). 
The Wavelets show it - the transit time of water varies in time

week and the concentration of chloride detected in the rainfall sample at the time of read-out. Chloride mass fluxes in runoff were calculated by multiplying the discharge at the 'Lower Hafren' gauging station and the concentration of chloride in the grab sample taken at a weekly sampling interval. Both time series of chloride fluxes were resampled to a common temporal resolution of 7 days.

\section{The Continuous Wavelet Transform}

Several attempts have been made recently to apply wavelet analysis to hydrometric and hydrochemical problems. For example, Weigand et al. (2017) applied CWT to relate temporal and spatial changes in dissolved organic carbon and nitrate concentrations. Another example is the paper of Onderka et al. (2013) where the authors used the CWT to estimate seepage velocities of water in stream sediments. Generally, two forms of wavelet transforms exist: the discrete wavelet transform, which gives a compact data presentation and is mostly used for the reduction and compression of noise, and its counterpart CWT (Weigand et al., 2017), which is more appropriate for the extraction of features, especially of complex time series containing noise. Since we seek a solution for the time-varying problem of TTD, we use the Continuous Wavelet Transform. A concise description of the wavelet analysis can be found e.g. in Farge (1992) or Torrence and Compo (1998). However, for the sake of clarity, we restrict ourselves here only to the description of CWT and its properties that are essential for the estimation of TTD. The main difference between the Fourier Transform and the Continuous Wavelet Transform is that wavelets are localized in both time and frequency. One can think of the difference also in terms of the Heisenberg Uncertainty principle, according to which, each wavelet reveals information about the temporal extent of the signal as well as about the frequency spectrum of the signal. The continuous wavelet transform (CWT) of a time series is essentially its convolution with the local basis functions, called 'wavelets' (Farge, 1992; Torrence and Compo, 1998). The wavelets can be stretched and translated to provide flexible resolution in both frequency and time (Torrence and Compo, 1998). The Continuous Wavelet Transform for a discrete sequence of measurements $x_{n}$ (e.g. tracer mass flux in our case) with equidistant spacing $\delta t$ is defined as the convolution product of $x_{n}$ with a dilated and translated wavelet $\psi(\eta)$ to balance the resolution between the time domain and frequency domain depending on a non-dimensional time parameter $\eta$ as:

$W_{n}^{X}(s)=\sum_{n}^{N-1} x_{n} \psi^{*}\left[\frac{\left(n^{\prime}-n\right) \partial t}{s}\right]$

where $W^{X}$ is the wavelet power, $n$ is the time index, $s$ is the wavelet scale, $\delta t$ is the sampling period, $N$ is the number of observations in the time series, and the asterisk indicates the complex conjugate. Since the above equation leads to complex wavelet coefficients (containing real and imaginary parts), the wavelet power spectrum $\left|W_{n}(s)\right|^{2}$ is a convenient way to describe the fluctuations of the variance of a signal at different times and frequencies. The Morlet wavelet is defined as:

$\psi_{0}(\eta)=\pi^{-1 / 4} e^{j \omega_{0} \eta} e^{-\eta^{2} / 2}$

where $\omega_{0}$ is the non-dimensional frequency $\left(\omega_{0}=6\right)$, as defined in Torrence and Compo (1998). A bias occurs at the beginning and at the end of the wavelet power spectrum because the wavelet is not completely localized in time (Grinsted et al.,
2004; Torrence and Compo, 1998). A cone of influence (COI) has been proposed to ignore the edge effects. The COI is an area in which the wavelet power caused by the poorly localized wavelet near the beginning and end of a time-series has dropped to $\mathrm{e}^{-2}$ of the wavelet power at the edge. Our wavelet analysis was implemented in the package of Matlab codes provided by Aslak Grinsted (https://github.com/grinsted/waveletcoherence) and the Torrence \& Compo codes (http://paos.colorado.edu/research/wavelets/). We used the Matlab workspace to further to process and analyze the variables (wavelet coherence power, phase, etc.).

Since we are interested in quantifying the relative time-lags between two wavelet traces, we use the cross-wavelet power to calculate the wavelet phase-difference. The time-frequency dependencies between the two time series of chloride can be analyzed by the cross-wavelet transform (XWT) of the two time series $x_{t}$ and $y_{t}$ as:

$W_{x y}=W^{X} W^{Y^{*}}$

where $W^{X}$ and $W^{Y}$ denote the wavelet transforms of $x_{t}$ and $y_{t}$, respectively. The asterisk indicates the complex conjugate of the series $y_{t}$. Then the phase-difference $\Delta \phi_{\mathrm{xy}}$ between the two time series at any point in time is defined as:

$\Delta \phi_{x y}=\arctan \left(\frac{I\left(W_{x y}\right)}{R\left(W_{x y}\right)}\right)$

where $I$ and $R$ in Eq. 4 refer to the imaginary and real parts of the WXT. Taking the inverse tangent of the ratio of the imaginary and real parts of the $X W T$ we obtain a phase difference between the two series anywhere between $-\pi$ and $+\pi$ (radians). A phase-difference of zero indicates that the two series are in perfect phase, i.e. moving together without any time-lag. If $\Delta \phi_{x y}$ is constrained by zero and $\pi / 2$, it is said that the time series $y_{t}$ leads $x_{t}$; and if $\Delta \phi_{x y}$ is constrained by $-\pi / 2$ and zero, then the time series $x_{t}$ leads the time series $y_{t}$. After calculating the phase differences for all time scales $(s)$ at all times $(t)$ we can define the 'instantaneous' time-lag $\Delta T_{x y}(s, t)$ between the two series, i.e. a time-lag calculated for every scale and for every point in time as:

$$
\Delta T_{x y}(s, t)=\frac{\phi_{x y}(s, t)}{\omega(t)}
$$

where $\omega(t)$ is the angular frequency corresponding to the wavelet scale $s$.

Since the CWT can be also used as a bandpass filter, the original signal can be reconstructed from the wavelet coefficients on a scale by scale basis. We used the procedure described in Torrence and Compo (1998) to decompose the original signal for all scales separately. The full reconstructed original signal is the sum of the individual decomposed components. Decomposing the signal into its frequency components makes it possible to analyze the contribution of the individual frequency components of the signal $\left(\kappa_{i}\right)$ to the total signal $\left(y_{\text {total }}\right)$ by:

$$
\kappa_{i}(s, t)=\frac{y_{s i}}{\sum_{i=n}^{i=m} y_{s i}}
$$

where $y_{s i}$ is the i-th frequency component $\left.i \in\langle n, m\rangle\right)$ of the full signal $y_{\text {total }}, n$ is the indexed beginning of the time-series and $m$ is the indexed end of the time series, $s$ refers to the scale, and 
finally $y_{\text {total }}=\sum_{i=n}^{i=m} y_{s i}$ is the full original signal.

The extent to which the chloride fluxes in runoff lag the rainfall fluxes of chloride was investigated scale by scale by analyzing the phases derived from cross-wavelet spectra. First, we derived the phase differences from the calculated crosswavelet spectra by applying Eq. 4 to the wavelet coefficients (Eq. 1). As we are interested in time-lags rather than the phase differences, the phases were transformed to time-lags by Eq. 5 .

To get a sense of how each frequency contributes to the overall signal variance, the basic filtering property of wavelets can be used. In this way the relative contribution of the individual frequencies to the whole signal is determined (Eq. 6). Now as we know to what extent the individual frequency components contribute to the total signal at time $t_{i}$ we can construct empirical distribution functions for the time-lags that are defined for each sampling time $t_{i}$. According to the law of mass conservation, the total mass that leaves the catchment has to equal the total tracer mass at the input (rainfall in our case); hence an instantaneous pulse of tracer can be translated into an output signal by convolving the input signal with a timedependent transfer function $g(t, \tau)$

$$
g(t, \tau)=\frac{c_{\text {out }}(t, \tau) Q_{\text {out }}(t, \tau)}{\int_{\tau}^{t} c_{\text {out }}(t, \tau) Q_{\text {out }}(t, \tau) d t}
$$

where $t$ is the time of leaving and $\tau$ is the time of entry; $c_{\text {out }}(t, \tau)$ is the output tracer concentration, and $Q_{\text {out }}(t, \tau)$ is the outflow volumetric flowrate. Note that the area under the integral in Eq. 7 has to equal to 1.0 :

$$
\int_{\tau}^{t} g(t, \tau) d t=1
$$

\section{Two-parameter Weibull distribution}

The Weibull distribution is a very flexible distribution model with two parameters, the $\beta$ shape parameter, $\lambda$ scale parameter, allowing the distribution to take on a broad range of shapes (Eq. 9):

$$
f(t)=\frac{\beta}{\lambda}\left(\frac{x}{\lambda}\right)^{\beta-1} \exp -\left(\frac{x}{\lambda}\right)^{\beta}
$$

where $\beta$ is the shape parameter and $\lambda$ is the scale parameter of the distribution function. A special case is when the Weibull distributions equals one $(\beta=1)$, i.e. when the Weibull distribution reduces to the exponential distribution. For $\beta<1$, the Weibull distribution decreases as a sharp exponential, while for $\beta>1$ the distribution becomes bell-shaped with long tails. We choose the Weibull distribution function due to its known flexibility in fitting empirical data; however, one could also consider the Gamma Function which has similar properties as the Weibull, and which has also been previously used in transit time modeling (e.g. Kirchner et al., 2000), or the Beta distribution as used in van der Velde et al. (2012). The median and mean values of the estimated transit times were calculated from the fitted Weibull distributions as: $\operatorname{TTD}_{\text {mean }}=\lambda \Gamma\{1+(1 / \beta)\}$ and $\mathrm{TTD}_{\text {median }}=\lambda\{\ln (2)\}^{1 / \beta}$.

\section{Instantaneous Transit Time Distributions}

The previously defined time-lags $\Delta T_{x y}(s, t)$ in (Eq. 5) and the individual frequency contributions $\kappa_{i}(s, t)$ in (Eq. 6) are used to estimate the transit time distributions for each point in time $t$ individually. Recalling that the TTD is essentially the time-dependent transfer function $g(t, \tau)$, (see Eq. 7), then by sorting the individual frequency contributions $\kappa_{i}(s, t)$ according to the time-lags $\Delta T_{x y}(s, t)$ in an ascending order one obtains an empirical form of the transfer function $g(t, \tau)$. We can now fit the Weibull distribution function (Eq. 9) to $g(t, \tau)$ to obtain Instantaneous Transit Time Distributions (ITTDs). Each Instantaneous Transit time Distribution is defined by its scale $\lambda(t)$ and shape $\beta(t)$ Weibull parameters.

\section{Master Transit Time Distribution}

To generalize the Instantaneous Transit Time Distributions defined above and to obtain a more integrated view on the distribution of transit times, the Master Transit Time Distribution (MTTD) can now be introduced. Our motivation to define the MTTD is that it merges all the ITTDs into a single distribution. The MTTD is defined here as the mean of all instantaneous transit time distributions. The rationale behind using the MTTD is that it can be thought of as a surrogate of a transit time distribution that could be derived from Fourier power spectra, as described e.g. in McGuire and McDonnell (2006). Moreover, the Master Transit time distribution allows us to compare our results estimates of the transit times with other authors who used the Fourier transform (Kirchner et al., 2001).

\section{RESULTS}

As expected, the chloride fluxes in runoff exhibit a smaller portion of high frequency components compared to the rainfall signal (Fig. 1a, b). This phenomenon has been already explained in Kirchner et al. (2000), i.e. the short-lived pulses of rainfall water are translated to the catchment outlet slowly, causing the input trace of water to stretch in time. Therefore the chloride fluxes at the catchment output fluctuate less than those at the input. We further looked at the cross-wavelet spectra of chloride fluxes in rainfall (Fig. 2) to see a strong and

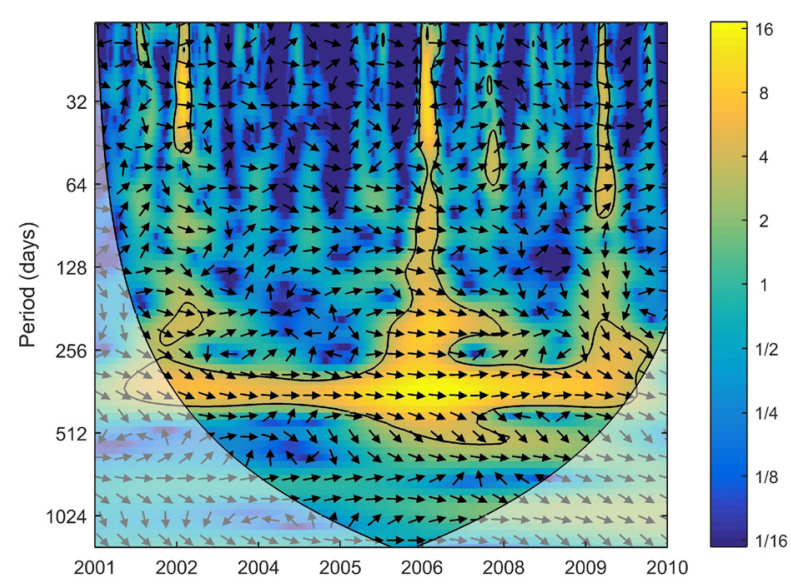

Fig. 2. The cross-wavelet power spectrum of chloride fluxes in rainfall and runoff. The contour level depicts the $95 \%$ significance level (tested against red noise). The colorbar placed on the right represents the squared power of the cross-wavelet transform. The phase arrows show the relative phasing of two time series. The arrow can be interpreted as a lead/lag. 

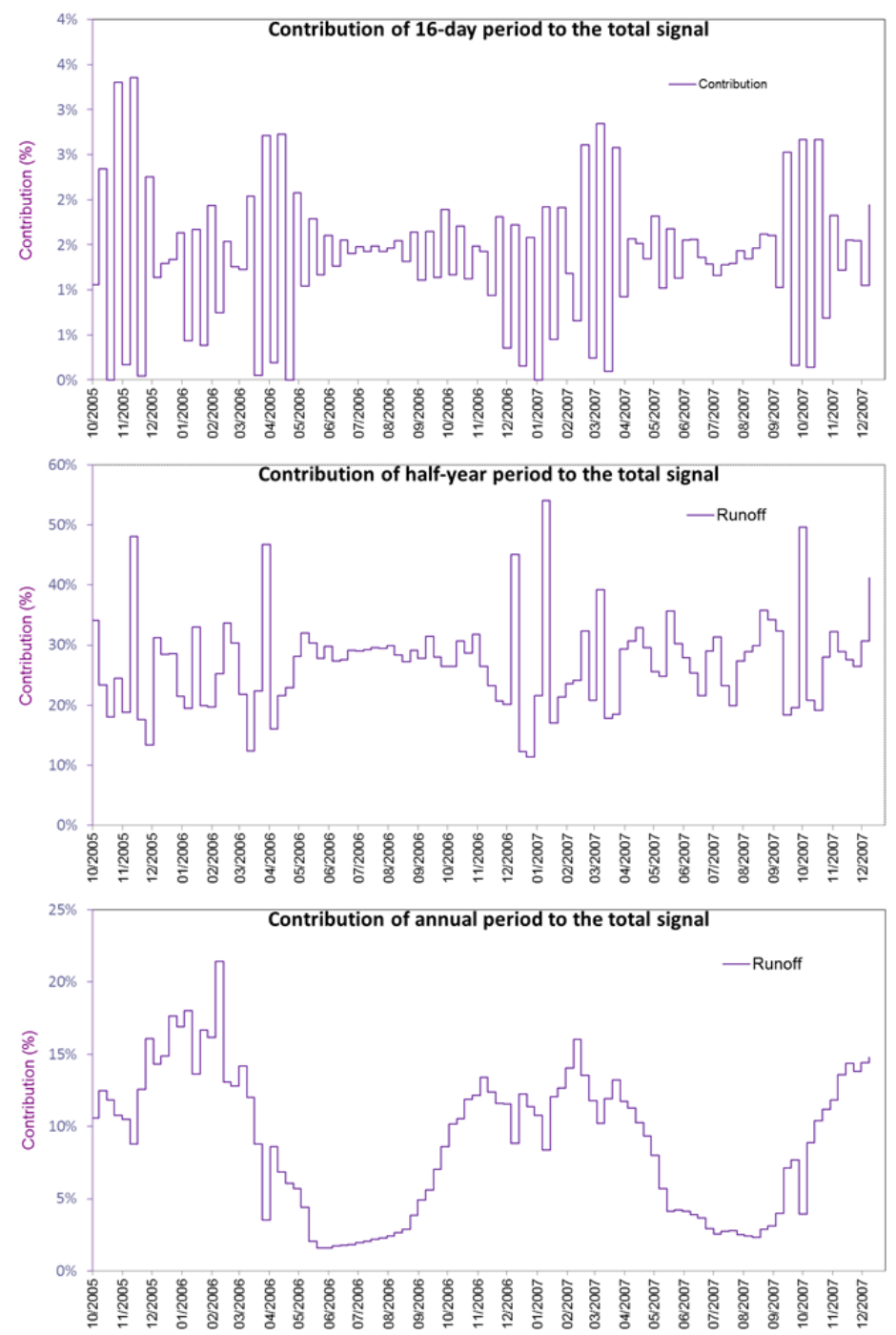

Fig. 3. Contribution of three (arbitrarily chosen) frequency contents $\left(y_{i}\right)$ to the total signal $\left(y_{\text {total }}\right)$ calculated from Eq. 6. (Upper plot) contribution of the 16-day signal; (Middle plot) contribution of the semi-annual period (6-months period) to the total signal; and (Bottom plot) contribution of the annual signal (12-month period) component.

statistically significant coherency between the rainfall and runoff signals with an annual periodicity, which is visible in the spectrogram as a high-energy region near the period of $\sim 50$ weeks (Fig. 2). The phase relationship is indicated by the orientation of the arrows (with in-phase pointing right, anti-phase pointing left). Since the phase-arrows point only in one dominant direction (to the right) at the annual period, we can say that the two series are phase-locked at periods around 365 days. Generally, the extent to which a certain frequency component contributes to the overall signal variance is visualized in Fig. 2 on the color bar. The annual frequencies located at period between 250 and 450 days (enclosed within the contour) are contain more energy and are red in color. The contribution of the reconstructed chloride fluxes in runoff to the total signal indicate (Fig. 3c) that this annual component contributes to the overall variance of the runoff fluxes of chloride by up to some $30 \%$.

The $\beta$ parameter of the Weibull distribution defines the overall shape of the distribution. We plotted the estimated $\beta$ parameters versus time and runoff (Fig. 6). By tracking the effect of runoff on the shape of the ITTDs, one can see that during and briefly after periods of high runoff episodes the $\beta$ shape parameter drops below 1.0, which indicates that the ITTD can change its shape dramatically from a bell-shape to an exponential.
After constructing the Instantaneous Transit Time Distributions for each time $t_{i}$, the Master Transit Time Distribution was calculated and plotted in Fig. 4. The MTTD is the defined as the mean of all ITTDs. The mean transit time calculated from the MTTD is 54.73 weeks, and the median is 40.79 weeks. This implies that $50 \%$ of water that has fallen on the catchment leaves the catchment via its stream outlet within 40.79 weeks ( 285 days). Finally, the mean and median values were calculated also for the ITTDs. Fig. 5 shows how the means and medians evolve in time.

\section{DISCUSSION}

Over the last 10 years, there was considerable progress in time-dynamic formulations of transit time distributions (Benettin, 2015a, 2015b; Botter et al., 2011; Harman, 2015; Heidbüchel et al., 2012; Hrachovitz et al., 2015; van der Velde et al., 2012). In spite of recent progress in studying the transport processes and pathways that vary over time and are site-specific (Herman et al., 2015), hydrological processes underlying observed water quality response patterns, such as the emergence of near-chemostatic conditions (Hrachowitz et al., 2015) are still not completely understood. While the notion of timevariant transit times is not entirely new (Benettin, 2015a, 


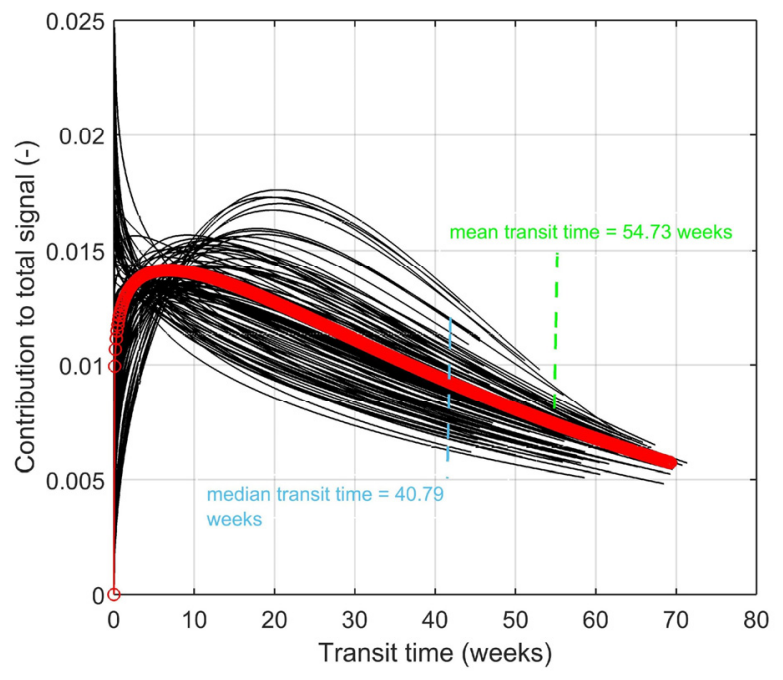

Fig. 4. Master Transit Time Distribution (red line) and the individual Instantaneous Transit Time Distributions - ITTDs (black curves). The mean transit time (calculated from the mean of all instantaneous transit time distributions ITTDs) is 54.73 weeks, with the median located at 40.79 weeks. The Weibull distribution parameters for the Master Transit Time Distribution: $\alpha$ scale parameter $=56.82$, and the shape parameter $\beta=1.106$.

2015b; Botter et al., 2011; Harman, 2015; Heidbüchel et al., 2012; Hrachovitz et al., 2015; Klaus et al., 2015; van der Velde et al., 2012), our approach is novel in that it is data-driven and capable of dealing with non-stationarities. This is the first time the Continuous Wavelet Transform is applied to estimate TTD.

Our analyses revealed that the mean of all transit times (Fig.
5 ) is 54.73 weeks (1.07 years), which is a slightly longer mean transit time than the $0.82 \pm 0.02$ years estimated by Kirchner et al. (2001) who applied the 2-parameter Gamma distribution on the Fourier power spectra of chloride data from the same catchment. However, it should also be noted that the difference in the mean transit time compared to static formulations may be small. The actual difference in the mean transit time may partially arise from the fact that Kirchner et al. (2001) analyzed an older period of record (1983-1997), while in this paper the results represent the period 2001-2012. Our results show that the transit time distribution is a dynamic catchment characteristic and that a single distribution function can be insufficient to describe the functioning of a catchment. Our observations agree with the most recent studies of other authors in terms that the assumption of a static TTD is not generally valid and that a predetermined distribution such as the gamma or exponential distributions that are often used to describe the TTD (Klaus et al., 2015). By means of the continuous wavelet transform and an example from the Lower Hafren catchment we showed that the TTD indeed varies with time. The Lower Hafren catchment has been extensively studied in the past, which made it possible to cross-check the results with already published studies. This paper shows that the instantaneous distribution of transit times may change abruptly depending on the wetness conditions.

Therefore a conclusion can be made that applying a distribution function with fixed parameters to the entire time series cannot adequately describe the behavior of the catchment. Fig. 4 illustrates that the family of the individual instantaneous distribution functions spreads over a wide interval. We merged the individual instantaneous distribution functions into a single empirical curve defining the 'mean' empirical distribution function - 'Master Transit Time Distribution'. From the

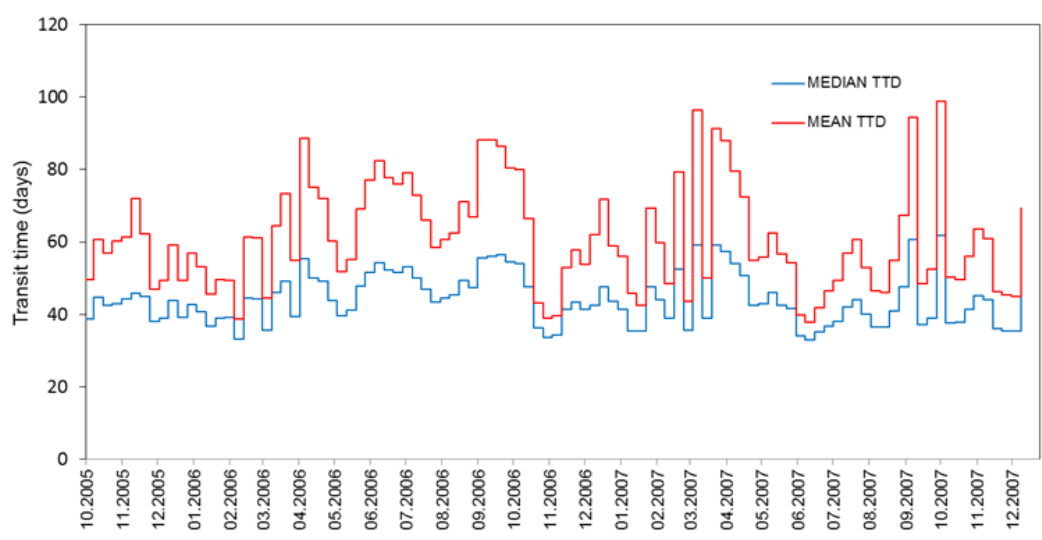

Fig. 5. Means and medians of the instantaneous transit time distributions (period 10/2005-12/2007).

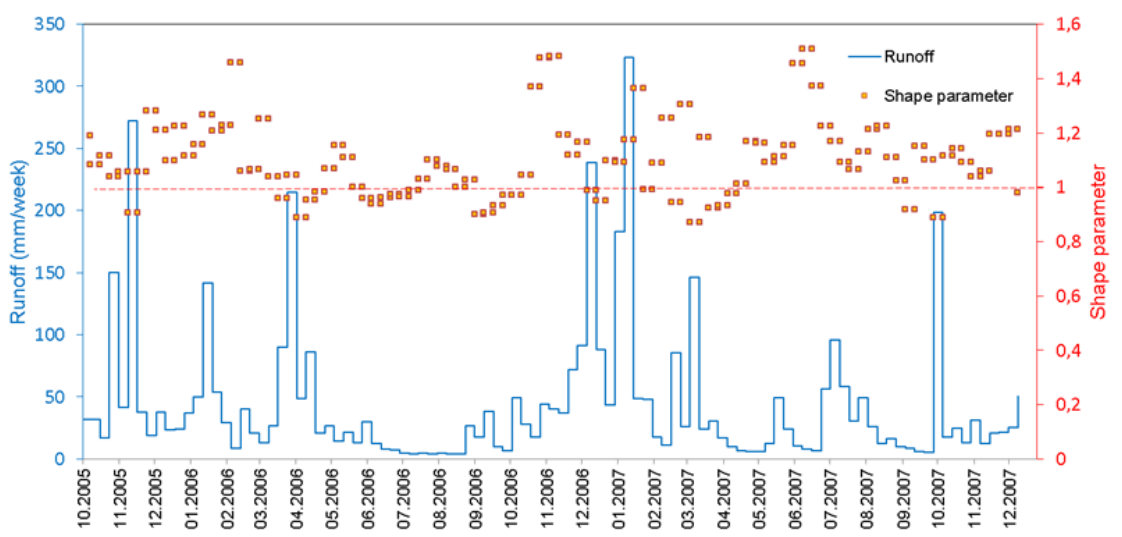

Fig. 6. Weibull shape $\beta$ parameter plotted along with the runoff (period 10/2005-12/2007). 
The Wavelets show it - the transit time of water varies in time

MTTD presented in Fig. 4 it is evident that it takes 'on average' $\sim 54.3$ weeks for rainwater to leave the catchment and pass the stream gauge at Lower Hafren. The MTTD has a long tail with the shape parameter $\beta=1.106$. This feature is observed in many catchments worldwide (Harman, 2015; Heidbüchel et al., 2012; Hrachovitz et al., 2010; Kirchner, 2016, Kirchner et al., 2000, 2001; McGuire and McDonnell, 2006; Tekleab et al., 2014). The long tail implies that a particle of water that landed on the catchment today will continue to affect the streamflow in small proportions for a long time. As water acts as the carrier, or solvent, for many chemical substances, the transit time distribution inherently affects chemical reactions, and thus affecting the water quality of groundwater surface waters with ultimate consequences for ecological functioning.

We showed that periods of elevated runoff are accompanied with an exponentially distributed transit times $(\beta<1)$. This may indicate a change in the diversity of water flow-paths and velocities during wet periods because contributing areas have been previously shown to shrink and expand depending on the duration of rainfall. Indeed, mechanistic and conceptual modeling in the Upper Hafren catchment by Benettin et al. (2015a, $2015 \mathrm{~b}$ ) showed that the storages involved in solute mixing affect the dynamics of travel time distributions and that most of the high-frequency fluctuations in the measured chloride concentration of stream water can be explained by the sharp transition between groundwater flows and faster flows originating from shallower storage layers driven by the inter-seasonal variability of atmospheric inputs.

\section{CONCLUSIONS}

The wavelet analysis as a technique is described and applied in this paper to shed light into the temporal aspects of transit time distributions. We showed that the continuous wavelet transform has the potential to remarkably increase our ability to visualize and analyze the temporal aspects of transit times. Decomposition of time series locally in both frequency and time provide a new view on temporal variability of TTD. It was not the goal of this paper to provide mechanistic explanations why TTD varies temporarily in the Lower Hafren catchment; nevertheless, we believe that the findings of this study have the potential to open a completely new avenue of research. The presented methodology has demonstrated the ability of wavelets to map the time-variant nature of water transit times. Advances in our understanding of the time-variant nature of water transit times are highly dependent in the development of novel methodologies that allow for the evaluation of such nonstationarities. However, such methodological advances should also aim at improving our understanding of the processes and mechanisms behind such catchment dynamics. Otherwise, new methodological tools will only be mere mathematical representations. In this paper we concentrated on the technical aspects of using the wavelets in the estimation of transit times. Physicsbased models and conceptual models require detailed knowledge about hillslope or catchment properties such as hydraulic conductivity of the soil for their use. Such detailed data is rarely obtainable and available. The conceptual models need some assumption on the mixing within the modelled catchment. The presented wavelet-based approach does not require such detailed information about the physical aspects of the investigated catchment. Our approach makes no assumptions about the shape of the transit time distribution. The advantage of such an approach is that detailed catchment property information is not needed which makes the approach relatively easy to apply over various hydrological scales. The wavelet analysis has the potential to become a practical diagnostic tool in studying the temporal evolution of hydrological processes under naturally time-variant conditions.

Acknowledgement. All real-world data (Plynlimon research catchment hydrochemistry) used and analyzed in this paper were downloaded from the web of the Centre for Ecology \& Hydrology (Environmental Information Data Centre). This resource is made available under the terms of the Open Government Licence: http://eidc.ceh.ac.uk/administration-folder/tools/cehstandard-licence-texts/ceh-open-government-licence/plain. The data are owned by NERC - Centre for Ecology \& Hydrology; (C) Database Right/Copyright NERC - (CEH).

\section{REFERENCES}

Benettin, P., Bailey, S.W., Campbell, J.L., Green, M.B., Rinaldo, A., Likens, G.E., McGuire, K.J., Botter, G., 2015a. Linking water age and solute dynamics in stream- flow at the Hubbard Brook Experimental Forest, NH, USA. Water Resources Research, 5111, 9256-9272. http://doi.org/10.1002/2015WR017552

Benettin, P., Kirchner, J.W., Rinaldo, A., Botter, G., 2015 b. Modeling chloride transport using travel time distributions at Plynlimon, Wales. Water Resources Research, 515, 32593276. http://doi.org/10.1002/2014WR016600

Botter, G., Bertuzzo, E., Rinaldo, A., 2011. Catchment residence and travel time distributions: The master equation. Geophysical Research Letters, 3811. http://doi.org/10.1029/2011GL047666

Davies, J., Beven, K., Rodhe, A., Nyberg, L., Bishop, K., 2013. Integrated modeling of flow and residence times at the catchment scale with multiple interacting pathways. Water Resour. Res., 49, 4738-4750. http://doi.org/10.1002/wrcr.20377

Duffy, C.J., Gelhar, L.W., 1985. Frequency domain approach to water quality modeling in groundwater: theory. Water Resources Research, 21, 1175-1184.

Dunn, S.M., McDonnell, J.J., Vaché, K.B., 2007. Factors influencing the residence time of catchment waters: A virtual experiment approach. Water Resources Research, 43, W06408. DOI: 10.1029/2006WR005393.

Farge, M., 1992. Wavelet transforms and their applications to turbulence. Annu. Rev. Fluid Mech., 24, 395-457.

Gomez, J.D., Wilson, J.L., 2013. Age distributions and dynamically changing hydrologic systems: Exploring topographydriven flow. Water Resour. Res., 49, 1503-1522. DOI: 10.1002/wrcr.20127.

Grinsted, A., Moore, J.C., Jevrejeva, S., 2004. Application of the cross wavelet transform and wavelet coherence to geophysical time series. Nonlinear Processes in Geophysics, European Geosciences Union EGU, 11 5/6, 561-566.

Harman, C.J., 2015. Time-variable transit time distributions and transport: Theory and application to storage-dependent transport of chloride in a watershed. Water Resour. Res., 51, 1, 1-30. DOI: 10.1002/2014WR015707.

Harman, C., Kim, M., 2014. An efficient tracer test for timevariable transit time distributions in periodic hydrodynamic systems. Geophysical Research Letters, 415, 15671575. http://doi.org/10.1002/2013GL058980

Heidbüchel, I., Troch, P.A., Lyon, S.W., Weiler, M., 2012. The master transit time distribution of variable flow systems. Water Resour. Res., 48, W06520. DOI: 10.1029/2011WR011293.

Hrachowitz, M., Soulsby, C., Tetzlaff, D., Dawson, J.J.C., Dunn, 2009. Using long-term data sets to understand transit 
times in contrasting headwater catchments. Journal of Hydrology, 367, 3, 237-248.

Hrachowitz, M., Soulsby, C., Tetzlaff, D., Speed, M., 2010. Catchment transit times and landscape controls - does scale matter? Hydrological Processes, 24, 117-125.

Hrachowitz, M., Fovet, O., Ruiz, L., Savenije, H.H.G., 2015. Transit time distributions, legacy contamination and variability in biogeochemical 1/f scaling: how are hydrological response dynamics linked to water quality at the catchment scale? Hydrological Processes, 29, 25, 5241-5256. http://doi.org/10.1002/hyp.10546

Kirchner, J.W., Feng, X., Neal, C., 2000. Fractal stream chemistry and its implications for contaminant transport in catchments. Nature, 403, 524-527.

Kirchner, J.W., Feng, X., Neal, C., 2001. Catchment-scale advection and dispersion as a mechanism for fractal scaling in stream tracer concentrations. Journal of Hydrology, 254, 82101.

Kirchner, J.W., 2016. Aggregation in environmental systems Part 1: Seasonal tracer cycles quantify young water fractions, but not mean transit times, in spatially heterogeneous catchments. Hydrol. Earth Syst. Sci., 20, 279-297.

Klaus, J., Chun, K.P., McGuire, K.J., McDonnell, J.J., 2015. Temporal dynamics of catchment transit times from stable isotope data. Water Resources Research, 516, 4208-4223. http://doi.org/10.1002/2014WR016247

Maloszewski, P., Zuber, A., 1983. Interpretation of artificial and environmental tracers in fissured rocks with a porous matrix, Report No. 1221/AP, Inst. Nucl. Phys., Krakow, Poland.

McDonnell, J. J., McGuire, K., Aggarwal, P., Beven, K. J., Biondi, D., Destouni, G., Dunn, S., James, A., Kirchner, J., Kraft, P., Lyon, S., Maloszewski, P., Newman, B., Pfister, L., Rinaldo, A., Rodhe, A., Sayama, T., Seibert, J., Solomon, K., Soulsby, C., Stewart, M., Tetzlaff, D., Tobin, C., Troch, P., Weiler, M., Western, A., Worman, A., Wrede, S. 2010. How old is streamwater?: Open questions in catchment transit time conceptualization, modelling and analysis. Hydrological Processes, 24, 12, 1745-1754.

McGuire, K.J., McDonnell, J.J., 2006. A review and evaluation of catchment transit time modeling. Journal of Hydrology, 330, 543-563.

McGuire, K.J., DeWalle, D.R., Gburek, W.J., 2002. Evaluation of mean residence time in subsurface waters using oxygen18 fluctuations during drought conditions in the midAppalachians. Journal of Hydrology, 261, 132-149.

McGuire, K.J., McDonnell, J.J., Weiler, M., Kendall, C., McGlynn, B.L., Welker, J.M., Seibert, J., 2005. The role of topography on catchment-scale water residence time. Water Resources Research, 41, 5. DOI: 10.1029/2004WR003657.

McMillan, H., Tetzlaff, D., Clark, M., Soulsby, C., 2012. Do time-variable tracers aid the evaluation of hydrological model structure? A multi model approach. Water Resources Research, 485. http://doi.org/10.1029/2011WR011688

Neal, C., 1997. A view of water quality from the Plynlimon watershed. Hydrology and Earth Systems Sciences, 13, 743753.
Neal, C., Reynolds, B., Norris, D., Kirchner, J.W., Neal, M., Rowland, P., Wickham, H., Harman, S., Armstrong, L., Sleep, D., Lawlor, A., Woods, C., Williams, B., Fry, M., Newton, G., Wright, D., 2011. Three decades of water quality measurements from the Upper Severn experimental catchments at Plynlimon, Wales: an openly accessible data resource for research, modelling, environmental management and education. Hydrological Processes, 25, 38183830. DOI: $10.1002 /$ hyp. 8191.

Neal, C., Kirchner, J., Reynolds, B., 2013. Plynlimon research catchment hydrochemistry. NERC Environmental Information Data Centre 10.5285/44095e17-43b0-45d4-a781aab4f72da025

Onderka, M., Wrede, S., Rodný, M., Pfister, L., Hoffmann, L., Krein, A., 2012. Hydrogeologic and landscape controls of dissolved inorganic nitrogen DIN and dissolved silica DSi fluxes in heterogeneous catchments. Journal of Hydrology, 450-451, 36-47.

Onderka, M., Banzhaf, S., Scheytt, T.J., Krein, A., 2013. Seepage velocities derived from thermal records using wavelet analysis. Journal of Hydrology, 479, 64-74

Soulsby, C., Birkel, C., Tetzlaff, D., 2014. Assessing urbanization impacts on catchment transit times. Geophysical Research Letters, 412, 442-448. http://doi.org/10.1002/2013GL058716

Soulsby, C., Birkel, C., Geris, J., Dick, J., Tunaley, C., Tetzlaff, D., 2015. Stream water age distributions controlled by storage dynamics and nonlinear hydrologic connectivity: Modeling with high-resolution isotope data. Water Resources Research, 519, 7759-7776. http://doi.org/10.1002/2015WR017888

Tekleab, S., Wenninger, J., Uhlenbrook, S., 2014. Characterisation of stable isotopes to identify residence times and runoff components in two meso-scale catchments in the Abay/Upper Blue Nile basin, Ethiopia. Hydrol. Earth Syst. Sci., 18, 24152431.

Torrence, C., Compo, G.P., 1998. A Practical Guide to Wavelet Analysis. Bull. Amer. Meteor. Soc., 79, pp. 61-78.

van der Velde, Y., Torfs, P.J.J.F., van der Zee, S.E.A.T.M., Uijlenhoet, R., 2012. Quantifying catchment-scale mixing and its effect on time-varying travel time distributions. Water Resources Research, 48, 6. DOI: 10.1029/2011WR011310.

van der Velde, Y., Heidbüchel, I., Lyon, S.W., Nyberg, L., Rodhe, A., Bishop, K., Troch, P.A., 2015. Consequences of mixing assumptions for time-variable travel time distributions. Hydrological Processes, 29, 16, 3460-3474. http://doi.org/10.1002/hyp.10372

Weigand, S., Bol, R., Reichert, B., Graf, A., Wiekenkamp, I., Stockinger, M., Luecke, A., Tappe, W., Bogena, H., Puetz, P., Amelung, W., Vereecken, H., 2017. Spatiotemporal analysis of dissolved organic carbon and nitrate in waters of a forested catchment using wavelet analysis. Vadose Zone Journal. DOI: 10.2136/vzj2016.09.0077.

White, R.E., 1987. A transfer function model for the prediction of nitrate leaching under field conditions. Journal of Hydrology, 92, 207-222.

Note: Colour version of Figures can be found in the web version of this article. 